\title{
Acoustic Characterization of Jet Interaction with Launch Structures During Lift-Off
}

\author{
N. Karthikeyan* and L. Venkatakrishnan \\ National Aerospace Laboratories, Bangalore, Karnataka 560 037, India
}

\begin{abstract}
DOI: $10.2514 / 1 . A 33616$
The structures that constitute the environment surrounding the launch vehicle affect the noise levels experienced by it during liftoff. Earlier studies modeled the launch scenario by incorporating a jet impinging on plate geometries, either flat or curved, ignoring contributions from the components of the launch structures such as the launch platform. Very little is known about the effect of the structures on the propagation of noise from the jet exhaust toward the vehicle. This renders any effort to modify them for noise reduction quite challenging. The present study attempts to address this concern by investigating the contribution of a principal launch structure component, namely, the launch platform, toward the acoustic and flowfield around a generic launch vehicle exhausting on a generic jet blast deflector. The measurements include flowfield visualizations and aeroacoustic measurements using microphones in the near and far field. The results indicate that the presence of the launch platform increased the noise levels experienced by the vehicle beyond certain $L / D_{e}$. It is also observed that replacing the solid launch platform with a perforated one leads to lower levels of noise compared to the solid one but still higher than the case where launch platform is absent.
\end{abstract}

\section{Nomenclature}

$D_{e}=$ diameter of the nozzle exit, $0.3175 \mathrm{~m}$

$L=$ nozzle standoff distance from the launch platform

\section{Introduction}

$\mathbf{T}$ HE most crucial phase during the initial ascent of any launch vehicle is during its liftoff from the launch platform. During this phase, the launch vehicle is exposed to the severest of the acoustic loads. Though only a small part of the total energy of the turbulent, high-temperature jet exhaust from the engine nozzles results in the noise generation [1], it entails significant attention because it manifests itself as intense dynamic acoustic loads, which can prove detrimental to the structural integrity of the launch vehicle itself and its delicate onboard electronic subsystems including the payload. The vehicle is invariably subjected to the acoustic loads until it clears the launch tower by at least a few nozzle diameters. The design and testing of the launch vehicle structure and its subsystems to withstand the liftoff acoustic loads is quite a daunting task in itself. Hence, any effort to reduce these loads can prove to be highly beneficial by directly influencing the design, weight, and qualification of the launch vehicle components and hence the vehicle operating cost and time. The immediate surroundings of a launch vehicle at liftoff generally consist of a jet blast deflector, a launch platform, and the umbilical tower. The launch support structures are expected to contribute toward the noise experienced by the launch vehicle by either reflecting the noise generated by the jet exhaust or creating additional sources of noise. The parameters like jet deflector geometry, impingement angle, and liftoff distance seem to play a critical role in determining the distribution of noise sources along the deflected jet. An accurate estimation of the acoustic loads on the vehicle, by characterizing the contributions from the launch support structures, is very much essential for devising suitable mechanisms for the noise mitigation at liftoff.

Initial efforts to estimate liftoff noise employed empirical methods, which were based on data collected from various motor firing tests,

Received 31 March 2016; revision received 21 July 2016; accepted for publication 18 October 2016; published online 10 February 2017. Copyright (C) 2016 by the American Institute of Aeronautics and Astronautics, Inc. All rights reserved. All requests for copying and permission to reprint should be submitted to CCC at www.copyright.com; employ the ISSN 0022-4650 (print) or 1533-6794 (online) to initiate your request. See also AIAA Rights and Permissions www.aiaa.org/randp.

*Scientist, Experimental Aerodynamics Division.

${ }^{\dagger} \mathrm{Head}$, Experimental Aerodynamics Division. Associate Fellow AIAA. scaled models test, and actual launches. The most widely adopted empirical methods are the two source allocation methods prescribed by Eldred [1] extending a prior work by Potter and Crocker [2]. Both methods of Eldred and Jones require inputs such as vehicle configuration, nozzle exhaust parameters, and simplified deflector geometry to estimate acoustic loads. Significant improvements to the methods have been suggested in recent times $[\underline{3}, \underline{4}]$ by using inputs from other computational and experimental efforts. Kudryavtsev and Safronov [5] developed a semi-empirical formulation for estimating the acoustic loads during a liftoff, deriving mainly from their earlier analytical work [6,7] on impinging jets. Though empirical models provide a quick and reliable conservative estimate of liftoff noise, they completely exclude the jet interaction effects with the launch support structures other than jet blast deflectors. They also lack the flexibility to include factors like vehicle drift on the launch platform, its shielding effects, water injection, etc.

From the perspective of detrimental effects of momentum and heat transfer at the point of impingement, an impinging jet is usually deflected using a jet blast deflector (JBD). Studies on the noise generated by jet impingement on JBDs find high relevance especially in the cases of aircraft carrier flight decks and launch vehicles. Immense literature [8-12] is available on the issue of noise generation and the accompanying lift loss due to impinging jets on a flat surface, a situation encountered with vertical take-off and landing aircraft. On the other hand, a JBD for the conventioal take-off and landing/short take-off and landing aircraft on the aircraft carrier flight decks is usually a simple inclined plane deployed behind the aircraft when it is about to takeoff. The acoustics of jet impinging on the inclined flat plate has also been well studied both computationally and experimentally [13-20]. For launch vehicles, the geometry of the JBD is fairly elaborate because it is required not only to deflect the jet from the engine exhaust but also to conduct it farther away from the from the launch vehicle, protecting it from the harsh effects of direct jet impingement. Though the mentioned studies present an insight into the underlying noise generation mechanisms of impinging jets, they rarely adopt a complex version of the JBD geometry like those used for launch vehicles, in that they hardly address the issues encountered during the actual launch. Also, they shed no light on interactions between the jet and other launch structures such as launch pad and their associated contributions toward the overall noise levels with the launch vehicle.

The need to accurately access the acoustic loads experienced by the launch vehicle at liftoff has driven the launch vehicle community to undertake complicated studies involving scaled-down launch vehicle models with high levels of fidelity [21-27]. Such studies like Ignatius et al. [23] even use small rocket motors that have properties 


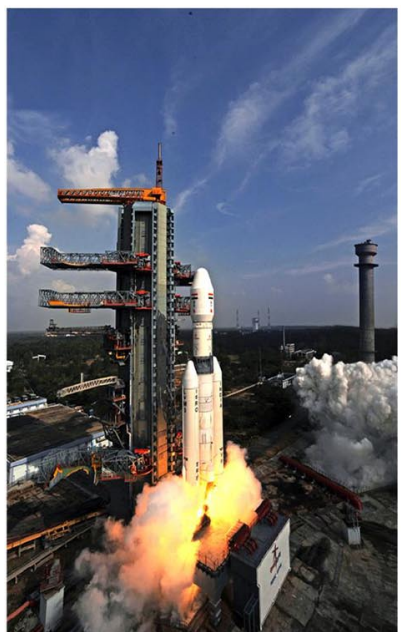

a)

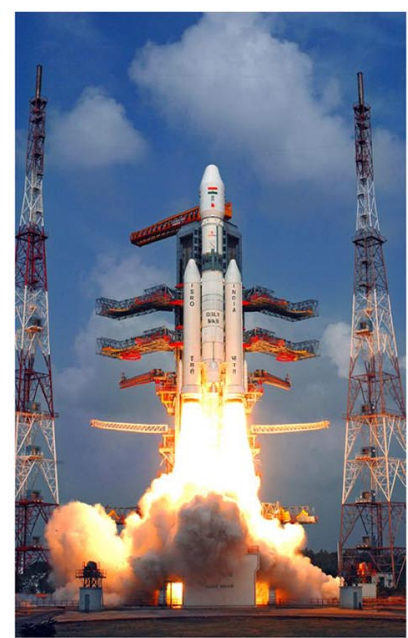

b)

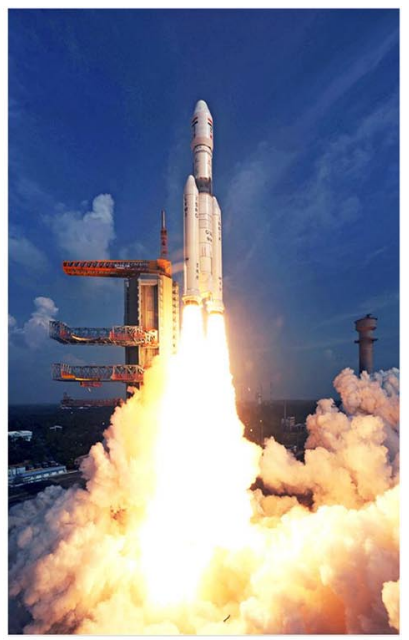

c)

Fig. 1 Lift-off of GSLV-MIII launch vehicle (courtesy http://www.isro.gov.in).

of the actual launch ones to achieve the thermodynamic simulation of the launch environment as effectively as possible. The main objectives of these studies range from determination of the effect of modifications of the flame trench (JBD) to optimization of water injection parameters. The results obtained from these studies have been shown to be highly reliable. However, the exorbitant cost and time scales involved in setting up such experiments prohibit any kind of parametric studies on the launch structures to quantify their contributions to the noise levels experienced by the launch vehicle. The flow over the launch platform, a primary launch structure, by itself presents a interesting case study. The launch platform (LP) or the launch pedestal provides the support on which the launch vehicle is readied for launch. It has cutouts that admit nozzles of the engines before liftoff. Upon ignition, as the launch vehicle ascends, the nozzles emerge from these cutouts. If one were to assess the flow from the rocket exhaust and its interactions with the launch pedestal occurring over the first few seconds after the ignition, three distinct patterns emerge.

1) The nozzles are inside the cutouts of the LP, and the jet exhaust flow impinges over the JBD and is deflected to emerge at ground level at far end of the JBD duct.

2) The nozzle has lifted off the LP, but the flow from the nozzle is such that the jet has increased in diameter (due to the jet growth), and it impinges on the platform partly, whereas the remaining flows through the cutouts and over JBD as before.

3) The vehicle has lifted off the LP considerably, and the jet now engulfs the LP, the surrounding ground, and the JBD.

All this activity, demonstrated in Fig. 1 , happens within the initial few seconds after ignition, while the vehicle is still to clear the umbilical tower. Hence, the flow over the launch pedestal is expected to be of some effect as far as the acoustic load experienced by the vehicle is concerned. A recent study on subscale-model test of Aries I launcher by Panda et al. [28] used the acoustic beam-forming technique on scale-model firings of Aries I to identify new sources of liftoff noise, namely 1) the gap between the LP and flame deflector (i.e., JBD), and 2) the impingement zone on the launch platform created by the ascent and drift of the vehicle. Their study showed these sources to be stronger than the flow through the jet deflector duct, during vehicle ascent. More importantly, the study established the fact that, apart from JBD, the LP too influences the noise levels on the launch vehicle.

Given the role of the LP during the launch, any characterization is incomplete without considering the cutouts in the LP. As attempted in previously mentioned studies, equating the flow over the LP to an impinging flow over a flat plate may not be an ideal realization of the launch scenario because the effects of cutouts are completely ignored. Kawai et al. [29] showed that the near-field acoustic levels generated by the jet impinging on flat plate are more than the ones generated by the jet impinging on a flat plate with a hole, though both exhibited similar spectra. They attributed the reduction in noise levels to the decrease in strength of the Mach-wave radiation, the principal noise-producing mechanism, when the hole is present. It is surprising that, apart from this study, there are no studies that characterize the fundamental aerodynamic and aeroacoustic aspects of the launch platform and its cutouts.

Water injection has been widely adopted by the launch community as an efficient technique to reduce noise levels during liftoff of the launch vehicle. A large amount of water, up to 3-4 times the mass flow from the engine exhausts [23], is pumped directly into the JBD at different points along the jet path and at locations above and below the launch platform (as the vehicle ascends) to minimize noise. The installation and operation costs of water injection systems are of great concern, particularly with the introduction of newer powerful launch vehicles. The system has to be optimized and redesigned for each launch vehicle engine configuration that is expected to be used at a given launch site. This limits the operative efficiency of the launch sites severely reducing their flexibility to launch vehicles of different configurations. Recently, there have been efforts to reduce liftoff noise using techniques other than water injection. Wiley et al. [30] investigated the noise from a jet impinging on a perforated plate. The perforations when combined with the microjet injection technique resulted in appreciable noise reduction. Based on an earlier work on distributed exhaust nozzles [31], Ahuja et al. [32] suggested that, in lieu of the jet blast deflector, a treated porous surface could be used as an impingement surface to achieve noise reduction at liftoff. These concepts have not yet been tested for their effectiveness in a launch vehicle environment due to the issues in their implementation.

The present study attempts to characterize the acoustic and flowfield contributions of the launch platform by simulating a generic launch vehicle environment inside an anechoic chamber. Both acoustic (near- and far-field) measurements and flow visualizations (shadowgraph) are carried out on a scaled-down generic launch vehicle jet deflector model with and without a launch platform. The vehicle liftoff has been simulated by varying the distance between the nozzle exit and the launch platform. The study also investigates the effect of replacing the solid launch platform (SLP) with a perforated launch platform (PLP) to assess its effects on the overall noise levels. The results from the study provide an understanding of the level of influence that launch structures, primarily the launch platform, have on liftoff noise.

\section{Experimental Setup}

\section{A. Acoustic Test Facility}

The experiments were carried out in the Jet Aeroacoustics Research facility at National Aerospace Laboratories. The facility is 


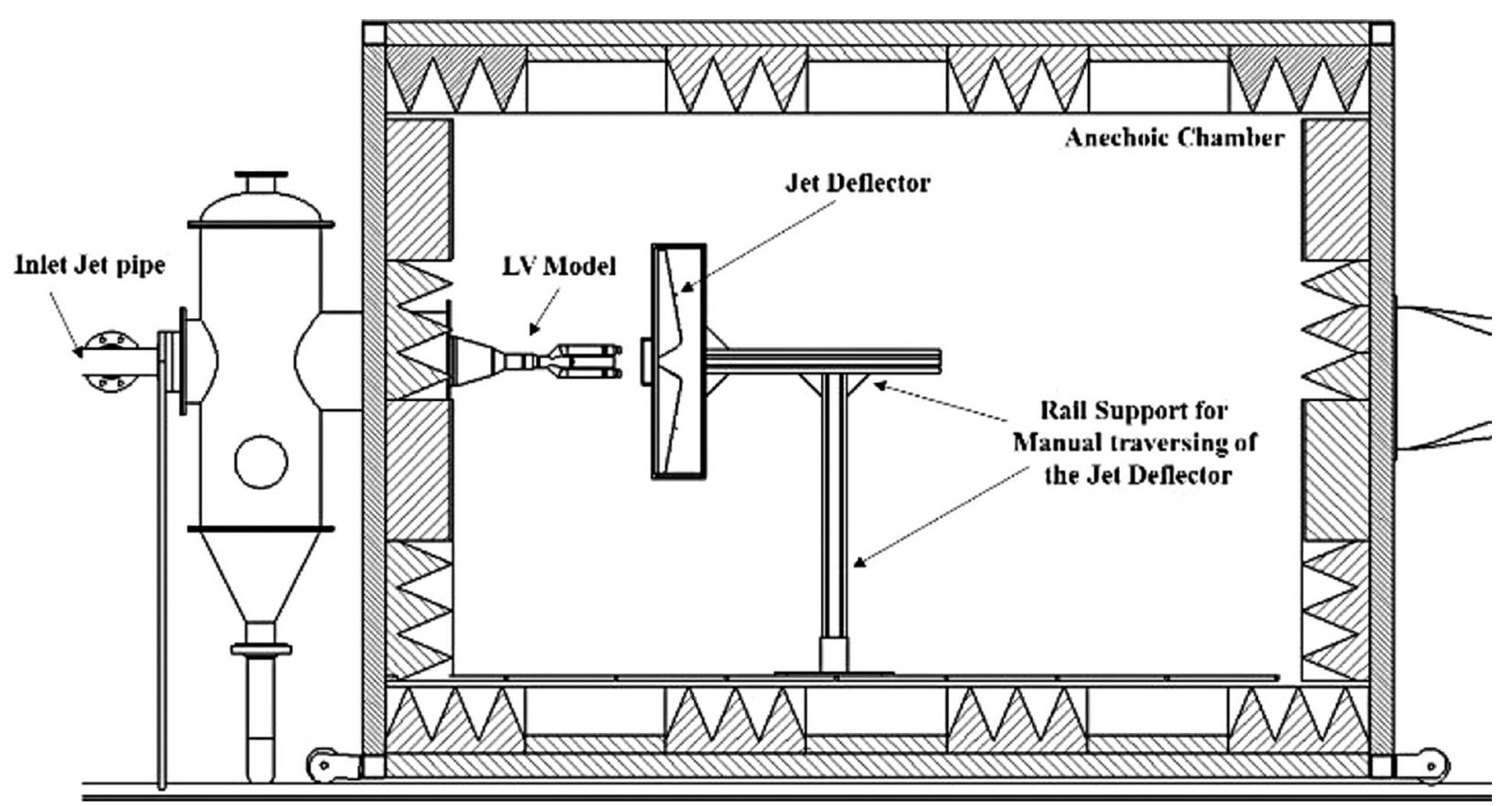

Fig. 2 Launch vehicle model assembly inside the anechoic chamber of jet aeroacoustics research facility.

designed to carry out acoustic measurements of jets issuing out of nozzles, single or dual-stream, exhausting into an anechoic chamber. The facility is supplied with dry compressed air from a 10 bar reservoir through a computerized globe valve (make: Fisher, type: ET) with a whisper cage trim (I) for cutting down on valve pings. The flow passes through a set of flow-conditioning devices inside the settling chamber consisting of a perforated cone and three sets of flow-conditioning screens before entering the chamber. The accurate control of the pressures is achieved by controlling the globe valve using a closed-loop proportional-integral-derivative control program developed in-house using LabView. This allowed jet driving pressure to be maintained within \pm 0.35 psi during the run.

The inner wedge-to wedge dimensions of the anechoic chamber are $3.6 \mathrm{~m}(\mathrm{~L}) \times 3.63 .6 \mathrm{~m}(\mathrm{~W}) \times 3 \mathrm{~m}(\mathrm{H})$. The walls of the chamber are fitted with fiberglass cloth covered acoustic wedges from Eckel Industries. Calibration studies carried out earlier showed that the chamber is anechoic above $400 \mathrm{~Hz}$ [33] even with the floor grating in place. The chamber is provided with suitably treated intakes to allow for entrainment by the jet. During the run, the ambient pressure in the chamber dropped by less than $0.1 \mathrm{psi}$, demonstrating that adequate area has been allowed for entrainment. A circular catcher of $0.6 \mathrm{~m}$ diameter with an acoustically treated lip provided for the outlet from the chamber. A schematic of the launch vehicle model assembled with the deflector inside the anechoic chamber is shown in Fig. 2.

\section{B. Model Details}

The configuration of the launch vehicle considered for the present study has been designed to closely simulate the geometry of the launch structures. The model consists of the following components; the launch vehicle, jet blast deflector, and launch platform. The model was designed to be modular so as to enable the investigation of acoustic contributions from each of the components separately. A CAD rendering of the model of launch vehicle and the launch environment components is shown in Fig. 3.

\section{Launch Vehicle Model}

The launch vehicle model is based on a commonly used, generic launch vehicle design consisting of two solid booster strap-ons attached to a central core. This configuration is more realistic than the single jet one and is also less complicated to simulate compared to the one with four or more strap-ons. The model is mounted on to the jet pipe of the facility using an adapter. The incoming pressurized air enters the model through the launch vehicle core part, where it is

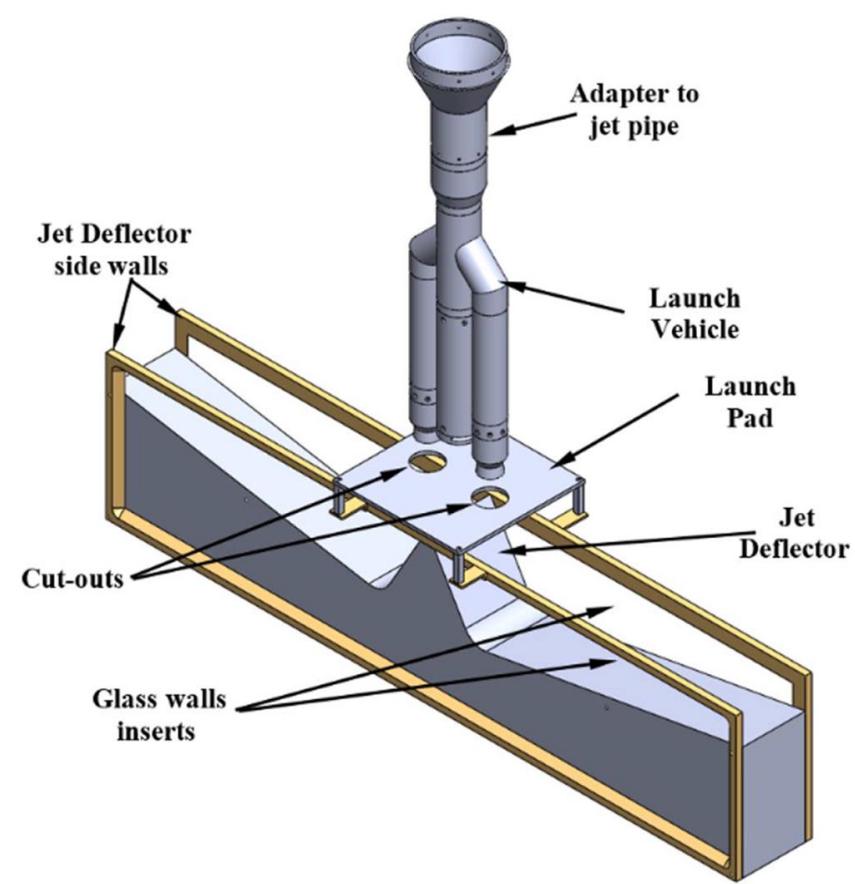

Fig. 3 CAD rendering of the various components of launch vehicle model used in the study.

internally divided into two streams that flow through the strap-on legs separately and exhausts through two separate nozzles. A hybrid approach has been used during fabrication of the model wherein the main body of the launch vehicle model is made of carbon fibre reinforced plastic, and the hard points for the attachment of the nozzles and the adapter are made of mild steel. This approach provided greater flexibility in fabricating the model and reduced model self-weight considerably.

\section{Jet Blast Deflector}

Because no open literature exists on the design of the jet deflector for launch vehicle applications, inspiration was drawn from [34]. A two-sided deflector was used such that jets from the two nozzles impinged on either side of the deflector separately at the initial launch 

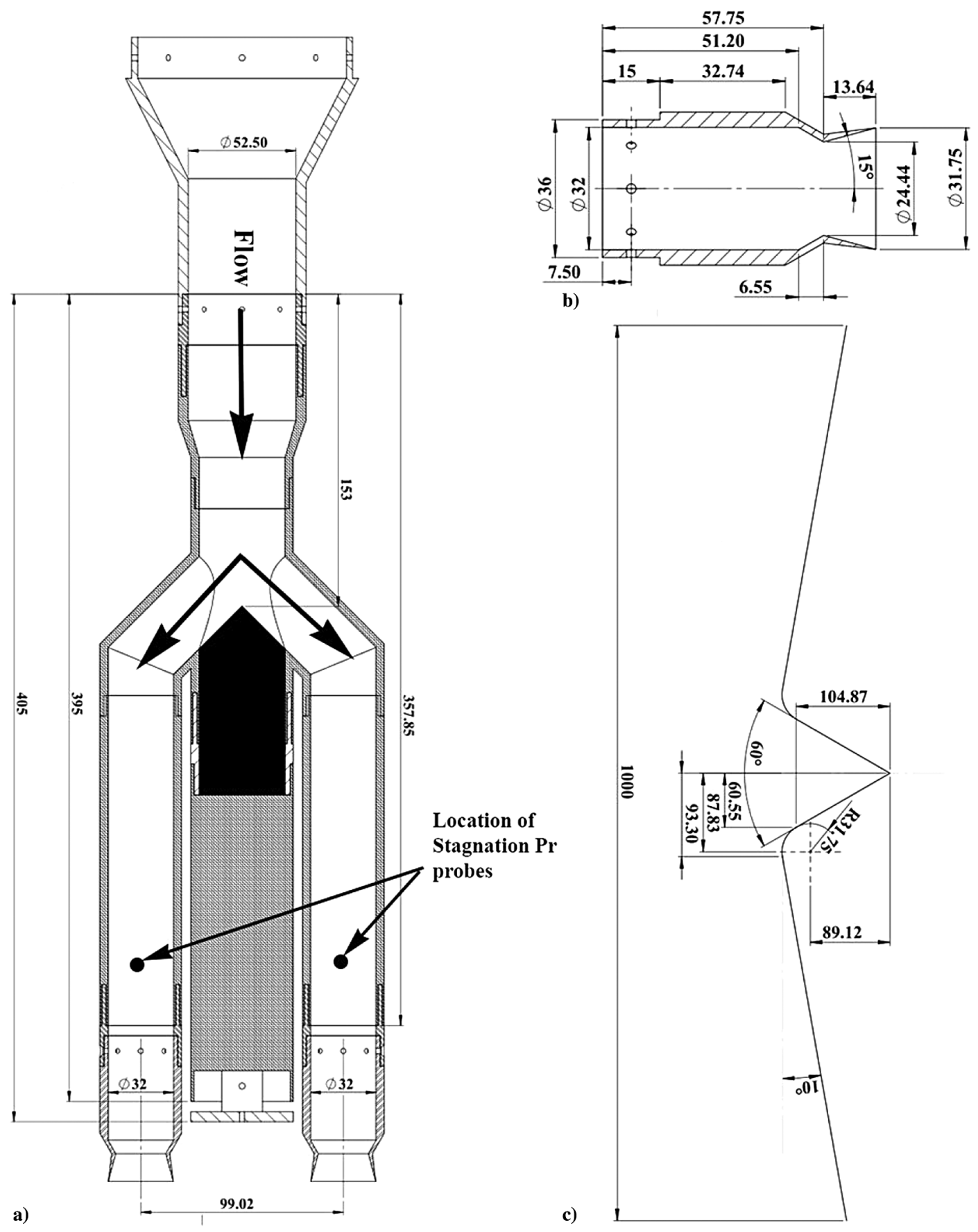

b)

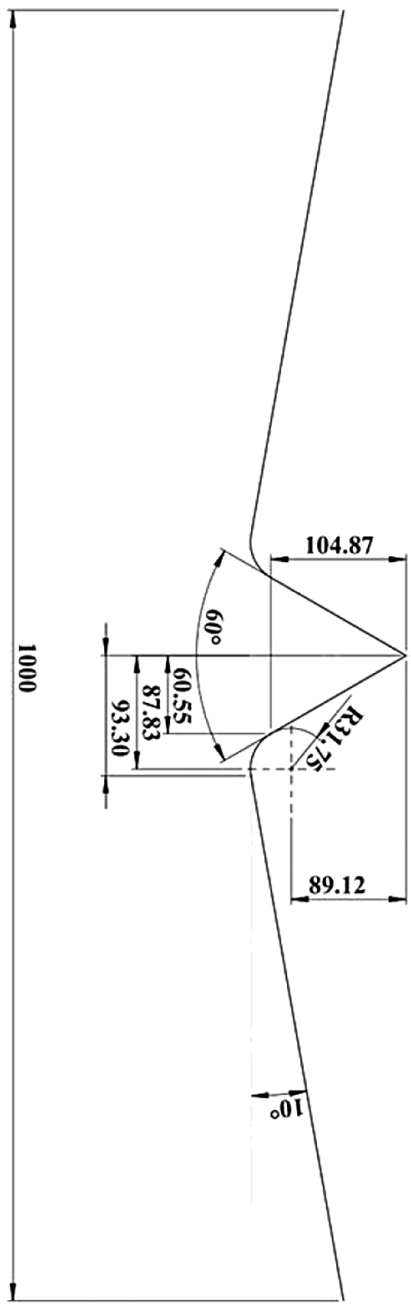

Fig. 4 Dimensions details of a) $L V$, b) $M=2.0$ nozzle, and c) JBD.

condition, when the nozzle exit plane remained inside the holes on the launch platform. The entire model has been designed to be modular such that the effects of JBD and the LP can be studied individually. However, compared to [34], two changes were made in the design of the deflector used in the present study. The turning radius at the end of the jet deflector slope is maintained at $1 D_{e}$ and the overall length of the jet deflector maintained at $1 \mathrm{~m}$. This resulted in the deflector exhaust plane not being level with that of the tip of the jet deflector, which is also the ground plane. This constraint was intentionally posed to prevent the deflected jet exhaust from affecting the top and bottom walls of the anechoic chamber. The side walls of the jet deflector have optical quality glass panels embedded in them, which provided for optical access for the flow visualization over the jet deflector surface.

\section{E. Jet Deflector Traverse Support}

The modularity of the jet deflector model enabled it to be mounted on a custom-designed support and traverse system assembled using
Bosch Rexroth aluminum profiles and a metallic base. The base, designed to both withstand the impact of impingement of the jets and take the weight of the deflector structure, was fixed rigidly to the floor of the anechoic chamber. The simulation of vehicle ascent was simulated by manually traversing the entire launch deflector away from the nozzle exit plane and that for the vehicle drift by locally adjusting the point of attachment of the jet deflector to the support.

\section{F. Launch Platform}

Two kinds of launch platform configuration were used in this study: 1) solid (SLP), and 2) perforated (PLP). Both configurations consist of a square mild steel flat plate of $200 \times 200 \mathrm{~mm}$, with two circular cutouts of $0.042 \mathrm{~m}$ diameter, just enough to allow the outer dimensions of the nozzle body $(0.040 \mathrm{~m})$. For the perforated launch platform, other than the two cutout holes, uniformly spaced holes (156 in number) of $10 \mathrm{~mm}$ diameter were drilled. The diameters of the holes and their distribution were decided such that they are uniformly 


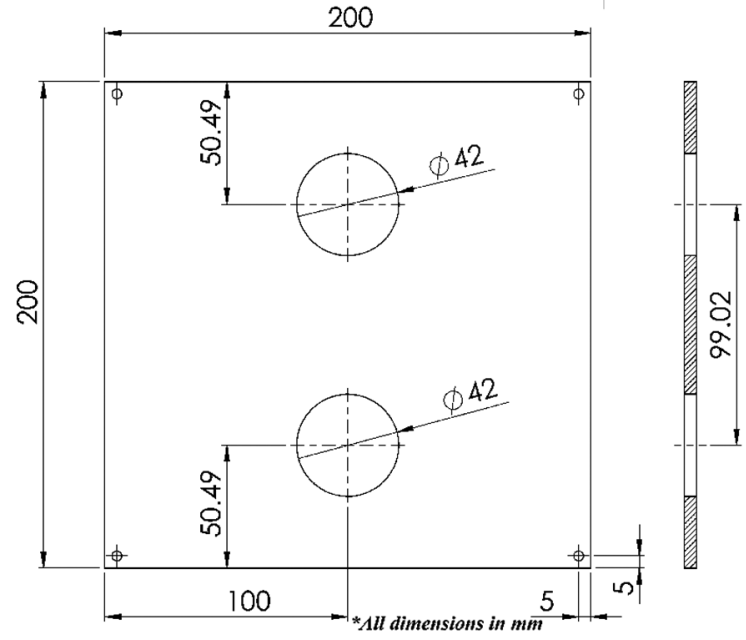

a) Solid launch platform

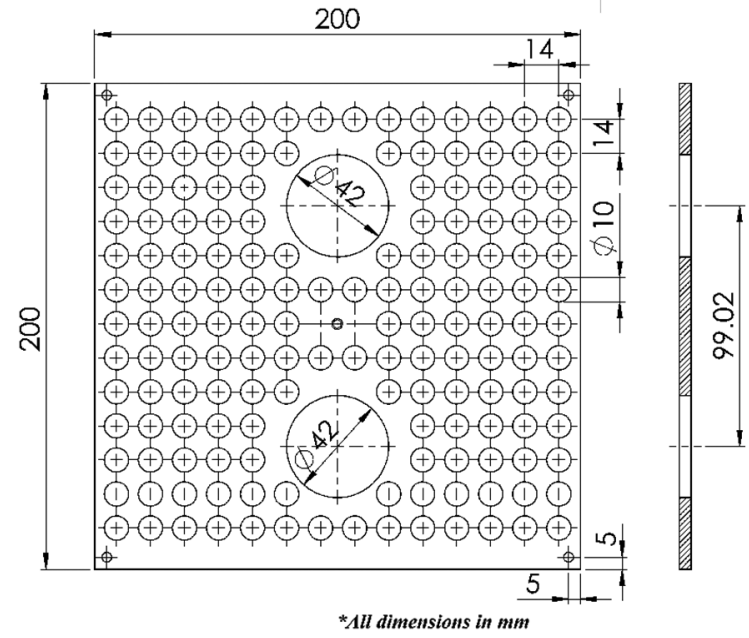

b) Perforated launch platform

Fig. 5 Launch platform configurations.

distributed and accounted for $\sim 33 \%$ reduction in solid blockage area of the launch platform plate. The launch platform plate was fixed to the walls of the jet deflector such that the distance from the bottom plane of the LP to the deflector tip was about $1.25 D_{e}$. The results of the aforementioned LP configurations are compared with the no launch platform (NLP) case.

\section{G. Nozzles}

Two identical nozzles were used in the present study, each one attached to one of the strap-on legs of the model. Conical nozzles were chosen to resemble a generic launch vehicle nozzle configuration. The design Mach number of the nozzles is 2.0. Each nozzle has an exit diameter of $0.03175 \mathrm{~m}$, which is used as reference length $D_{e}$. Pitot probes are provided ahead of each of the nozzles to monitor the stagnation pressures achieved during each run.

The dimensional drawings of the model components are shown in Figs. $\underline{4}$ and $\underline{5}$. During initial experiments, it was found that, in spite of JBD length constraints imposed during the design of the deflector, the flow from the jet deflectors affected the wedges as well as the top and bottom of the anechoic chamber. To prevent damages to the wedges, flexible pipes were added to the ends of the deflector to guide the flow exiting from the deflector away from the wedges into the exhaust duct. Figure 6 shows pictures of the actual realization of the model assembly on the traverse inside the anechoic chamber.

\section{H. Instrumentation}

\section{Acoustic}

The launch vehicle community is generally concerned about near-field acoustic levels at two principal locations on the launch vehicle: 1) on the launch vehicle body very near to the nozzles, which present severest of the acoustic loads, and 2) payload fairing, where sensitive electronics and payload are situated. The concern is directly reflected in subscale-model tests or actual flights, where recordings are made to obtain a measure of acoustic levels at these locations by instrumenting them with pressure field microphones [35]. Considering these facts, two sets of near-field acoustic measurements in the present study were carried out on the Launch Vehicle (LV) model with 1/4-in.-diam B\&K ${ }^{\circledR} 4939$ free-field microphones.

The first set consisted of three microphones (LV1, 2, and 3), distributed azimuthally at 90 deg intervals on the launch vehicle model at a location that corresponds to the payload fairing on a generic launch vehicle. A suitable mounting adapter was fabricated to hold the microphones in place on the surface of the LV. Dimensional details of the locations of near-field microphone arrays are shown in Fig. 7. A 90 deg bend adapter from GRAS ${ }^{\circledR}$ was used between the preamplifier and the microphone cartridge for each of these microphones so that the microphones are held normal to the LV surface. Such an arrangement, shown in Fig. $\underline{8}$, was preferred because it simulated the measurement environment at similar locations in other studies [23] as closely as possible with available microphone instrumentation at hand. This approach also allowed for comparisons of the obtained measurements with data from studies conducted elsewhere, at least qualitatively. Because of the orientation, microphone LV1-3 are at grazing angles of incidence to noise sources generated downstream from the jet as well as its interactions with the deflector and the launch platform. A second array of five microphones (AR1-5) were placed in a vertical line array facing the flow over deflector matching the deflector centerline. These microphones were at normal incidence. No near-field microphone measurements were attempted near the nozzles. The far-field measurements were carried out through a single microphone (FF1) placed facing the model in line to LV3 at about $60 D_{e}$ from the plane containing the model centerline. The grids on all the microphones were retained for the purpose of safety. The corrections for grazing
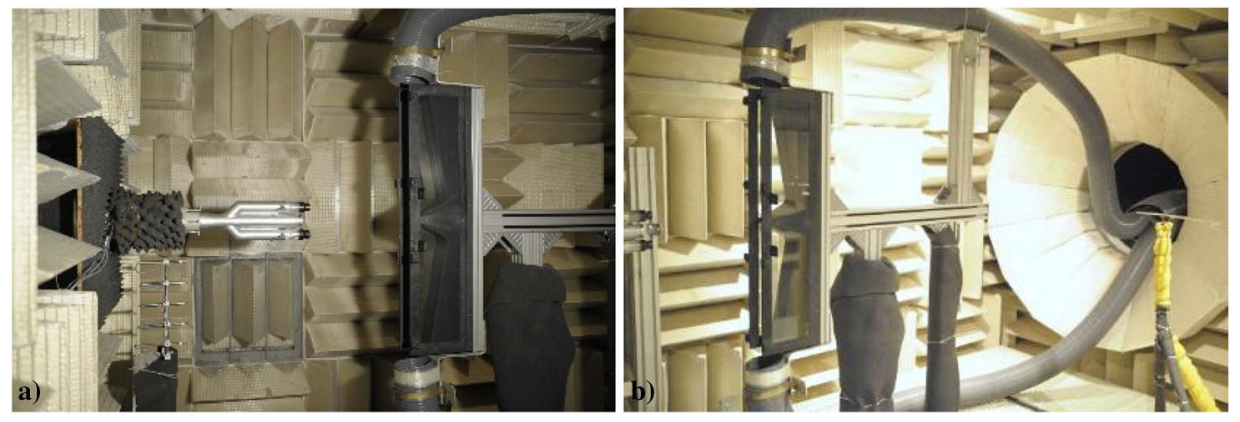

Fig. 6 View of a) the model inside the anechoic chamber, and b) the pipes taking out exhaust from the deflector. 


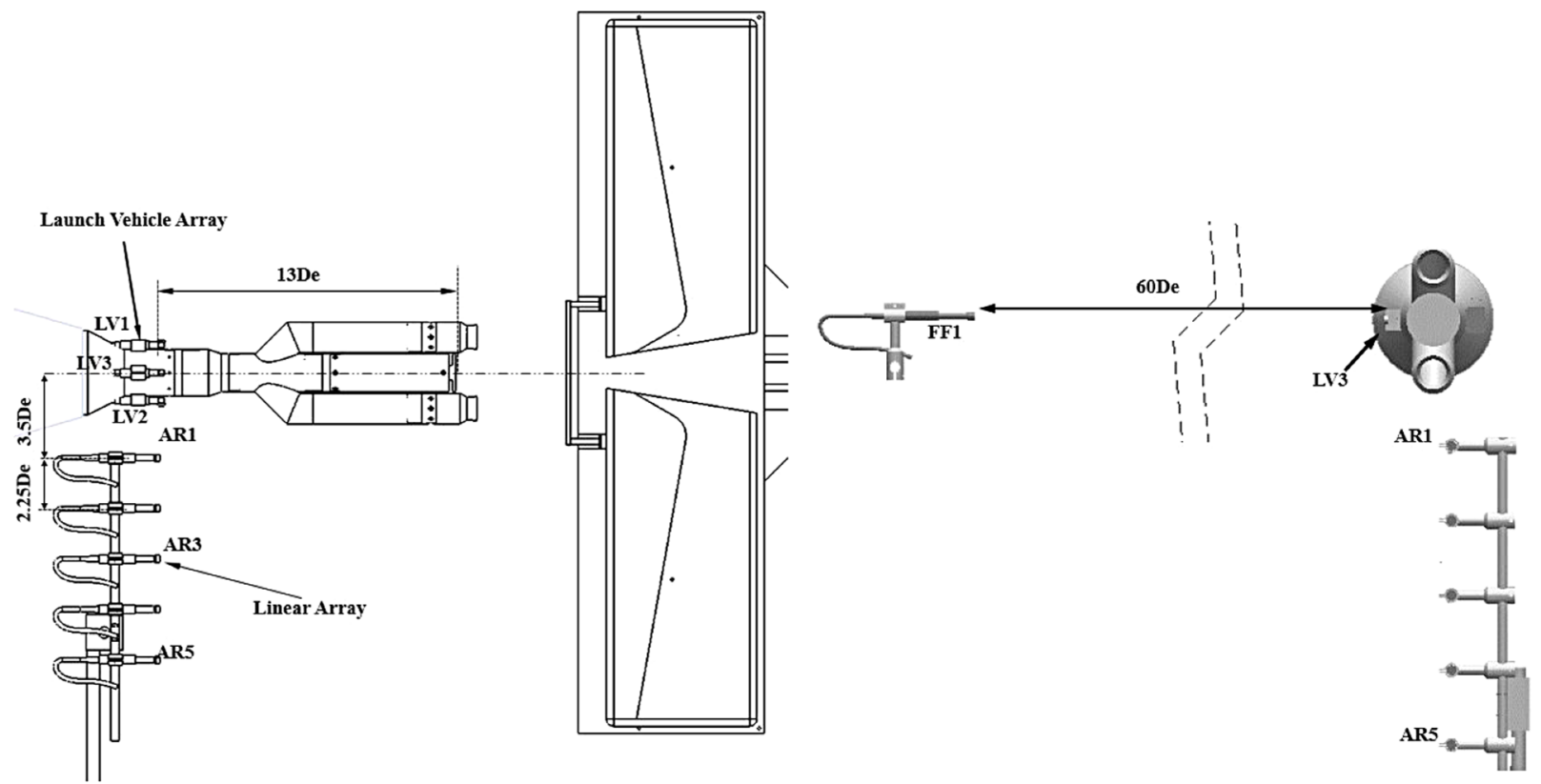

a) Side View

b) End View

Fig. 7 Details of microphone location with respect to the launch vehicle model.

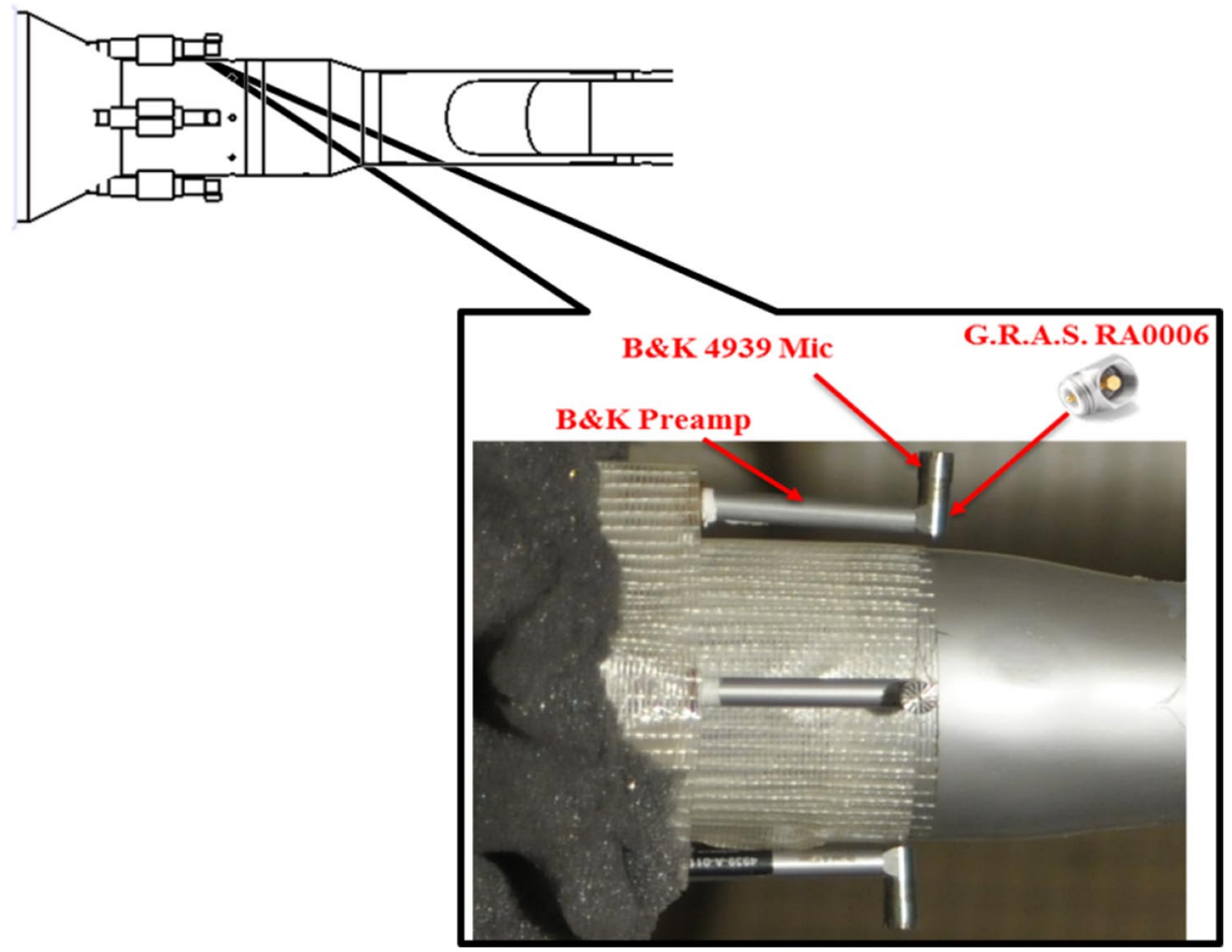

Fig. 8 Close-up of the microphone mounting in the LV array.

incidences and the presence of the grid on microphones, available from the manufacturer, were applied during postprocessing of the data.

All the microphones were calibrated with the B\&K 4228-type piston phone before the experiments. The data acquisition was carried out through a B\&K LAN XI simultaneous data acquisition system. Both near-field and far-field acoustic data were gathered during the study. The sampling rate was set at $262.144 \mathrm{kHz}$. At each microphone location, 786,432 samples were collected spreading over $3 \mathrm{~s}$ and analyzed with a 4096 point fast Fourier transform (FFT) and averaged. Averaging the results for the 192 FFT subsets reduced the random error in the calculation to within $0.1 \%$. The resulting resolution of the narrowband spectra is $64 \mathrm{~Hz}$. The sound pressure level (SPL) is defined in the conventional manner, $\mathrm{SPL}=20 \log _{10}\left(p_{\text {rms }} / p_{\text {ref }}\right)$, where $p_{\text {ref }}$ is taken as $20 \mu \mathrm{Pa}$. The overall sound pressure level (OASPL) was calculated by numerical integration of the spectra.

\section{Flow}

Three stagnation pressure probes were monitored during the course of the study: one directly available in the jet pipe before the inlet to the adapter to the jet pipe, and one each in the strap-on legs immediately upstream of the nozzles (Fig. 4a). This was to ensure that 


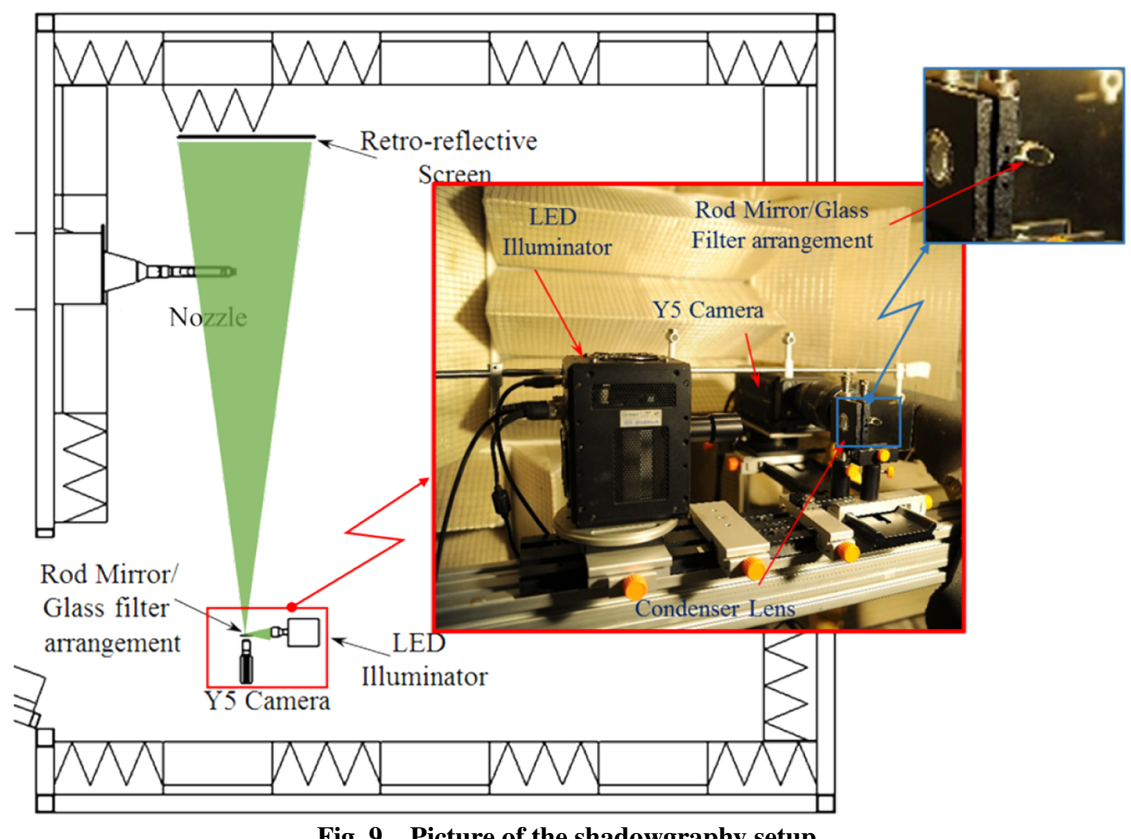

Fig. 9 Picture of the shadowgraphy setup.

the stagnation pressure at the nozzle inlet is correctly set so that the desired Mach number at the exit of the nozzles is achieved. These pressure ports are connected to separate DRUCK ${ }^{\circledR}$ pressure transducers, data from which were acquired through National Instruments analog input modules and processed with LabView program integrated with facility control software.

\section{Shadowgraph Setup}

A retroreflective type shadowgraph was set up (Fig. 9) inside the anechoic chamber to capture the flowfield changes brought about due to the presence of the launch platform. The setup was of coincident double-pass shadowgraph type adapted from the work of Hargather and Settles [36] with slight modifications. Presently, light from a highpower light-emitting diode (LED) illuminator is used as against the high-power lamp suggested in [36]. The light is converged onto the mirrored surface of a $45 \mathrm{deg}$ rod mirror fitted on to a thin glass plate fixed ahead of an IDT ${ }^{\circledR}$ Y5 Camera. The reflected light from the rod mirror illuminated a region large enough to capture the jet from the nozzles, their impingement on the launch platform, and to some extent the deflector itself. The illuminator is able to provide a short-duration ( $5 \mu \mathrm{s}$ ), high-energy light pulse, which was sufficient to uniformly illuminate the area of interest. The generation of light pulse was synchronized with the exposure of the camera fitted with a Nikkor $70-110 \mathrm{~mm}$ lens to enable recoding for the duration of illumination.

\section{J. Test Conditions}

Generally, at lift-off, the nozzles of a launch vehicle operate in an over-expanded condition. However, in the present study, the experiments were conducted at ideal operating conditions of the nozzle. This is due to the fact that, even at these ideal operating pressure ratios, the flow field of a conical nozzle exhibits shocks, unlike for a C-D nozzle, as the flow leaves the exit at an angle. Studies by Munday et al. [37], have shown that the acoustic characteristics of jets from conical nozzles is very much similar to those from C-D nozzles, except that it is dominated by broad band shock associated noise at all operating pressures. Also, in actual scenario, the launch vehicle nozzles operate with much higher exit Mach numbers $\left(M_{e} \sim 3.0\right)$. To simulate launch conditions realistically, it was decided to conduct the experiments at a pressure ratio that corresponds to highest jet exit Mach number is achievable with the nozzle and the experimental setup $\left(M_{j}=2.0\right)$, which is also the ideal operating conditions of the nozzle. Further, by operating at the design conditions, we would be operating at a pressure ratio which yielded higher noise levels than at over-expanded conditions. Hence the nozzle pressure ratio (NPR), i.e., jet stagnation to ambient pressure, was maintained at 7.82. The reference atmospheric pressure and temperature conditions were taken to be $13.25 \mathrm{psi}\left(91,355 \mathrm{~N} / \mathrm{m}^{2}\right)$ and $300 \mathrm{~K}$, respectively. A stagnation pressure of about $103.6 \mathrm{psi}$ $\left(714,396 \mathrm{~N} / \mathrm{m}^{2}\right)$ was required at the model inlet to achieve ideal expansion at the nozzle exit. However, the splitting of a single stream into two separate streams resulted in pressure losses being observed when readings from total pressure probes ahead of the two nozzles were compared with the total pressure at the inlet to the model. Hence, the inlet stagnation pressure to the model was increased to account for the losses, such that the total pressures ahead of the nozzle were maintained at $103.6 \mathrm{psi}$. The driving parameter of this study, $L / D_{e}$ is defined as the ratio of the distance between the nozzle exit plane and the launch platform top surface. In this study, three $L / D_{e}$ locations $(4,8$, and 12$)$ are investigated.

\section{Results and Discussions}

\section{A. Flow Visualization}

Though flow visualizations were carried out over the different LP configurations and $L / D_{e}$ positions, only the shadowgraphy results for the $L / D_{e}=8$ case are presented here because they clearly portray the influence of the LP on the flowfield. Figures $10 \mathrm{a}-10 \mathrm{c}$ show the shadowgraph images for the $L / D_{e}=8$ with no launch platform (NLP), solid launch platform (SLP), and perforated launch platform (PLP) configurations. In all the cases, the flow at the exit of the nozzles, the shock cells, impingement on the launch platform (if present), and the flow over the jet deflector are well captured in the shadowgraph. As mentioned in the earlier section, the flow at the exit of the nozzles is not parallel and not shock-free even at ideal expansion NPR of 7.82. The double shocks at the exit are in accordance with earlier studies of Munday et al. [37], on the flowfield of an ideally expanded conical nozzle. In the case of NLP, the entire jet directly impinges on the jet deflector and is turned on to itself due to the local inclination of the deflector. The ensuing shock structure on either side of jet deflector surface is seen clearly. Figure 10a shows that the two jets have not grown enough to merge and interact with each other before impinging on the JBD, at least at this $L / D_{e}$ location.

Figure 10b shows the shadowgraph of the flowfield in the presence of the solid LP. An outline of the LP with the cutouts has been 


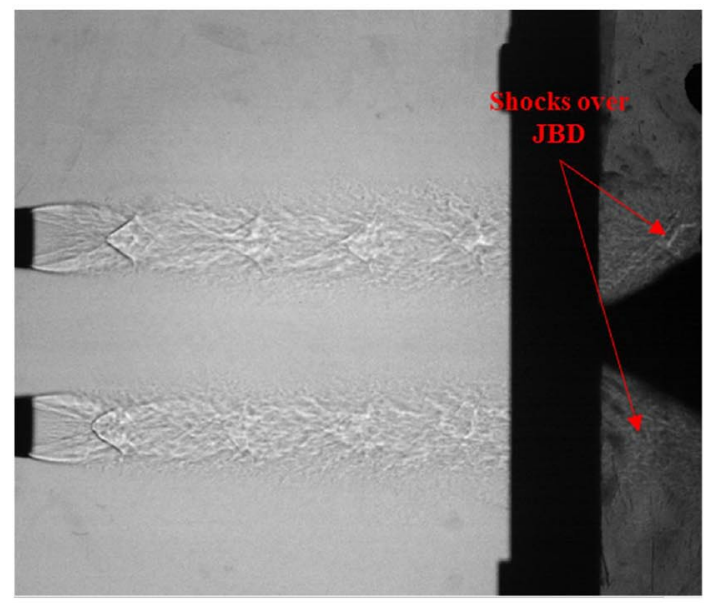

a) No LP

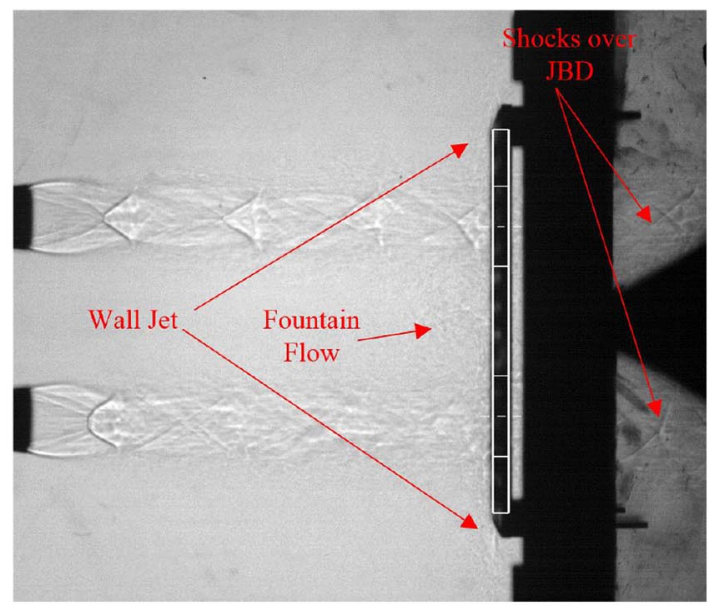

b) Solid LP

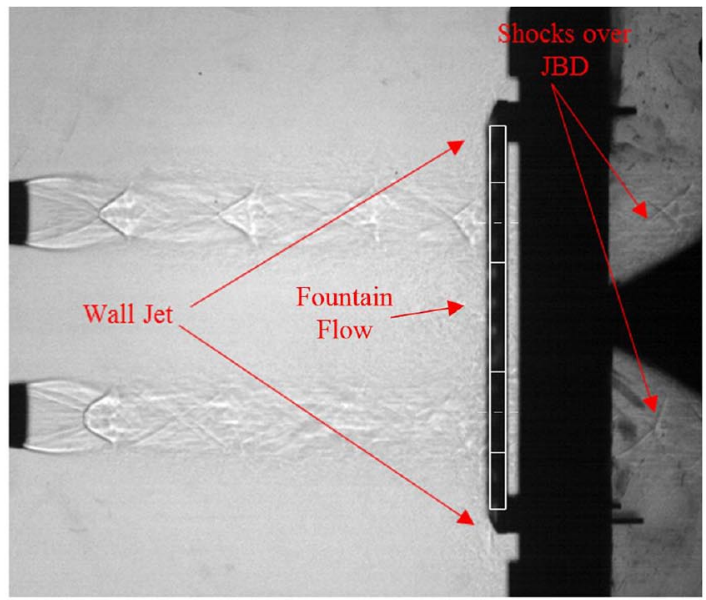

c) Perforated LP

Fig. 10 Shadowgraphy images of flow over different LP configurations.

superimposed over the image for clarity. It is observed that the introduction of the launch platform brings about significant modifications to the flowfield. A major portion of the jet after passing through the cutouts deflects over the JBD, creating shock structures akin to the NLP case. The jets, having grown bigger than the size of the cutouts in the LP, spill over and create wall jets, emanating radially outward, along the upper surface of the platform on the sides of the cutouts. The interaction of the wall jets from the two jets results in a strong fountain flow on the platform in the region between the cutouts. The shadowgraph of the flowfield in the presence of the PLP (Fig. 10c) also shows a similar flowfield. However, the spillover and the strength of wall jets formed along the LP surface seem to be much diminished in comparison to the SLP case. The reduced strengths of the wall jets result in reduced fountain flow in between the cutouts.

The images from flow visualization studies indicate that the flowfield in the presence of the LP, whether solid or perforated, is altered considerably compared to the NLP case. The presence of the fountain flow, observed in the SLP and in a weakened form in the PLP, has a significant impact on the noise levels, as will be seen in the next section.

\section{B. Acoustic Measurements}

Figures $11 \mathrm{a}$ and $11 \mathrm{~b}$ present the variation of OASPL values for each LP configuration, with different $L / D_{e}$ positions for the far-field array FF1 and the near-field array LV1-3. At FF1, the OASPL increases with $L / D_{e}$ for all the cases of LP configurations (Fig. 11a). As expected, the NLP configuration has the least of the OASPL values at all $L / D_{e}$, considering the influence of the LP observed in the shadowgraph results. At all $L / D_{e}$, the OASPL values for the SLP case is found to be higher than the NLP case by $2 \mathrm{~dB}$. A slight deviation is observed at the $L / D_{e}=12$ case, where the PLP configuration has slightly reduced noise levels compared to the other two.

The near-field measurements on the launch vehicle are shown in Figs. $11 \mathrm{~b}-11 \mathrm{~d}$. It is observed that, for the NLP case, only a marginal increase in OASPL values is observed, whereas for cases with LP, perforated or otherwise, the values show an increasing trend with increase in $L / D_{e}$. An increase in OASPL of $2.5 \mathrm{~dB}$ is observed for the solid LP case between $L / D_{e}$ of 4 and 12 at all microphones LV1-3. For the perforated platform case, an increase of $1.5 \mathrm{~dB}$ between $L / D_{e}$ of 4 and 12 at all microphones LV1-3. As shown in Fig. 5, the microphones LV1 and LV2 are placed diametrically opposite on the launch vehicle axis and should record identical values. However, the values at LV2 are consistently higher than LV1 readings at all conditions compared to LV1 by around $1.5 \mathrm{~dB}$. Before the experiments, it was expected that LV3 would have lesser values than LV1 and LV2 because it is perpendicular to the jet axis plane, which is likely to contain the noise sources. For a given $L / D_{e}$, the OASPL values for the SLP case are the highest among the different configurations, followed by the PLP and the NLP cases in that order. This pattern is observed for all microphones LV1-3. The OASPL values for the SLP case rise as high as $4 \mathrm{~dB}$ above the NLP case at $L / D_{e}$ of 12 .

It should be noted that both the far-field microphone FF1 and the near-field microphones on the launch vehicle (LV1-3) are at grazing incidence to the main noise sources: the free jet issuing out of the nozzles and its interactions with LP. Such a mounting gives uniform weighting to all noises as against free-field microphones mounted at 

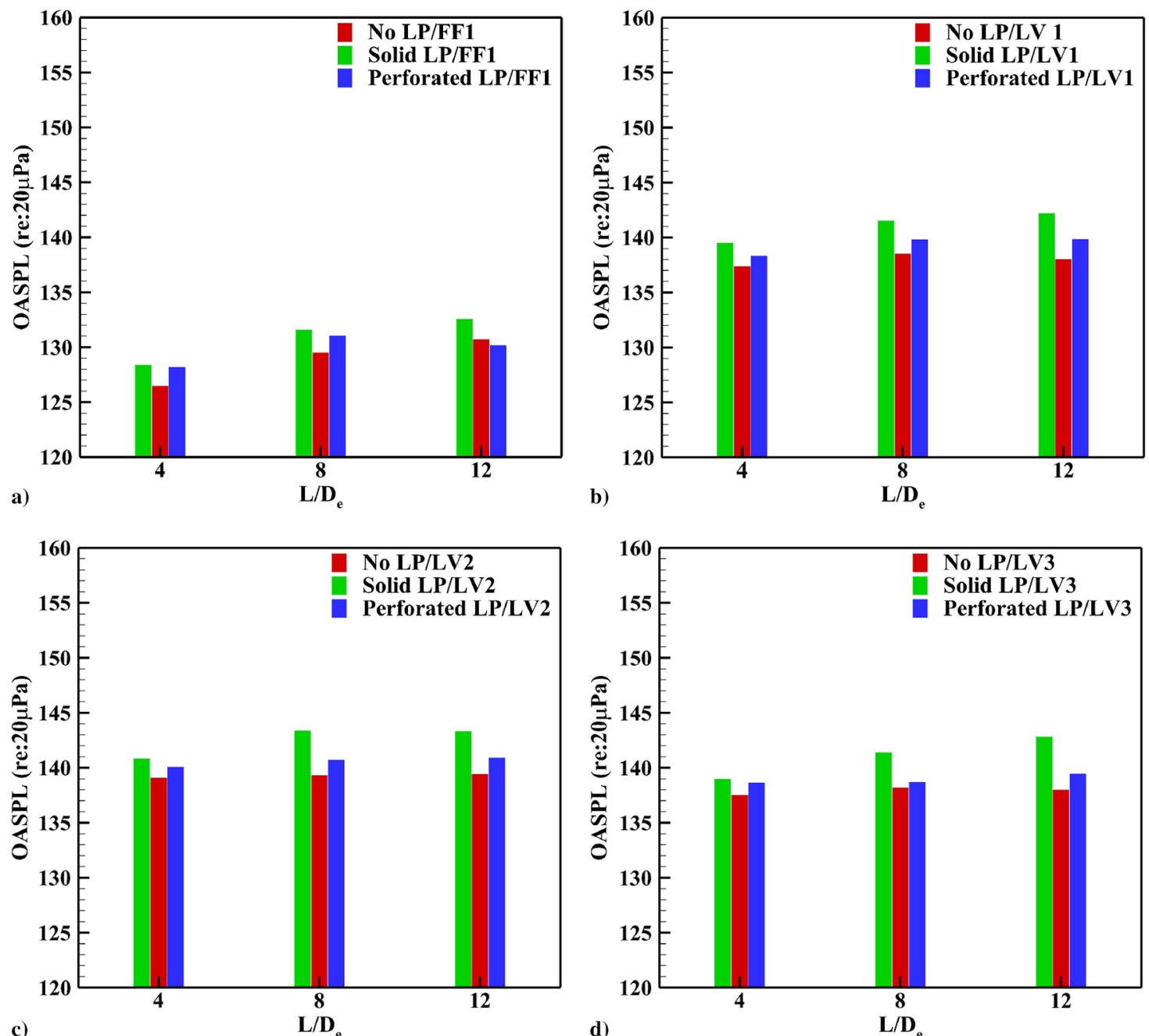

Fig. 11 Comparison of overall sound pressure levels a) far field, and b-d) launch vehicle array LV1-3.

normal incidence, which lay more emphasis on the noise sources to which they are pointing directly [35]. Hence, the linear array microphones are expected to capture the change in noise levels due to noise impingements directly. Figures $12 \mathrm{a}-12 \mathrm{e}$ show the OASPL comparisons at different $L / D_{e}$ locations for each of microphones AR1-5 along the linear microphone array. One can immediately notice that OASPL magnitudes recorded for all the microphones from AR1 to AR5 are nearly identical. It is also observed that the levels measured by the linear array microphones are considerably higher when compared to the microphones LV1-3 on the launch vehicle, due to the reasons discussed before. Second, unlike the results from LV1-3 and FF1, the OASPL decreases as the $L / D_{e}$ is increased for almost all the configurations. This can be attributed to fact that the distance between the microphones and the noise sources increases with increase in $L / D_{e}$. The decrease observed is not uniform over the LP configurations. For the SLP case, increasing $L / D_{e}$ from 4 to 12 , only a marginal (less than $1 \mathrm{~dB}$ ) decrease in seen, whereas for the other LP configurations, reduction observed is of the order of $2-3 \mathrm{~dB}$. Consistently at all locations, the NLP case has the least of OASPL. The measurements from AR1-5 also show that the perforated launch platform performs better than the solid launch platform case with comparatively lower OASPL at all $L / D_{e}$ locations.

For all the microphones in the linear array, the SLP case shows an increased OASPL of $2 \mathrm{~dB}$ at $L / D_{e}=4$ when compared to NLP case. The difference in OASPL increases to up to $4 \mathrm{~dB}$ at $L / D_{e}=12$. These results correlate well with the recordings from microphones LV1-3, discussed in the preceding paragraphs. The preceding observation is important because it shows that the growth of the jet and its increased interactions with the launch platform as $L / D_{e}$ increases causes the OASPL to rise compared to the no launch platform case. Though the OASPLs for PLP case are considerably higher compared to the NLP case for microphones AR1-5, they are at least $2 \mathrm{~dB}$ lower compared to the SLP case at the corresponding $L / D_{e}$. The preceding results suggest that the launch platform contributes significantly to the overall noise levels experienced by the launch vehicle, especially at higher $L / D_{e}$, and cannot be overlooked in studies on the effect of launch structures on noise levels experienced by the launch vehicle.

Figures 13a-13c shows the comparison of sound pressure level (SPL) spectra of the data from linear microphone array AR1. The comparison brings out clearly the role played by the LP in altering the noise directed toward the launch vehicle. Figure 13a shows that the effect of launch platform is less perceivable at $L / \overline{D_{e}}=4$. At this $L / D_{e}$, the jet boundaries are well within the cutouts in the platform such that most of the flow passes through them. The noise spectra are almost identical with slight increase observed in noise levels at frequencies greater than $5 \mathrm{kHz}$ with the $\mathrm{LP}$, either solid or perforated, over the NLP case. At $L / D_{e}=8$ (Fig. 13b), we see that SPL levels of the SLP case are higher than the NLP case at almost all the frequencies. This combined with the flow visualization results at corresponding $L / D_{e}$ shows that, with the jet diameter growing larger that the than the LP cutouts, their spillover and the subsequent jetlaunch platform interaction result in additional noise sources, as expected. Interestingly, the PLP case exhibits similar values of SPL of the NLP case until about a frequency of $5 \mathrm{kHz}$, after which a transition is seen, where the SPL level gradually increases, finally matching the levels comparable to that of the SLP case at $20 \mathrm{kHz}$. At the higher $L / D_{e}$ of 12 (Fig. 13c), a similar trend comparable to $L / D_{e}=8$ case 

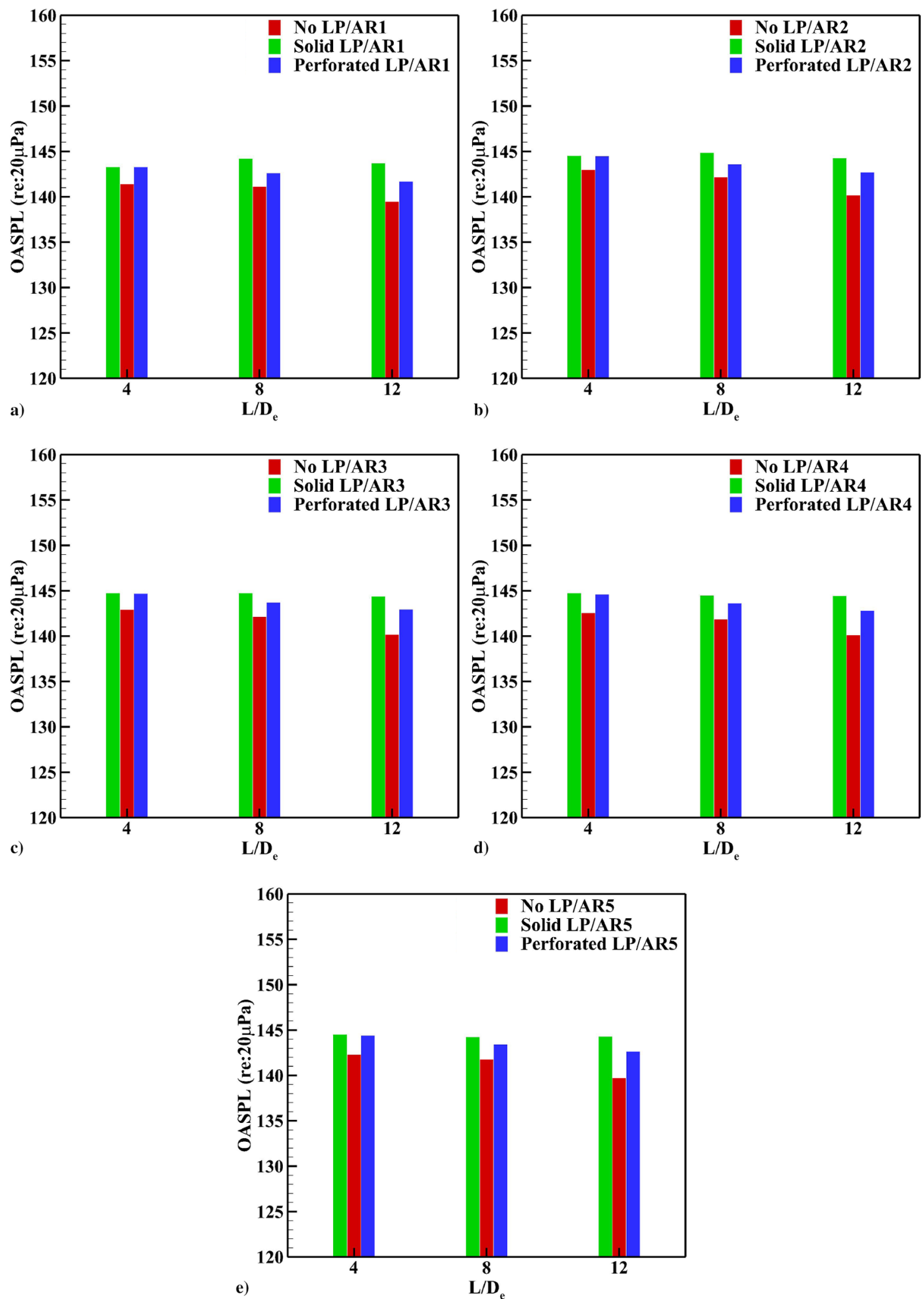

Fig. 12 Comparison of overall sound pressure level among linear array (AR1-5) microphones.

is observed. As the jets have grown much bigger than the cutouts at $L / D_{e}=12$, a higher influence of LP is implied from the increase in noise levels. The SLP case exhibits higher SPL over all the frequencies compared to the NLP case consistently, increasing up to a difference of $10 \mathrm{~dB}$ at $2 \mathrm{kHz}$. The PLP case exhibits the same transitioning trend as observed at $L / D_{e}=8$, with values being lower than the SLP, matching NLP at frequencies lower than $20 \mathrm{kHz}$ and gradually increasing to match the levels of SLP at higher frequencies.
The results from the acoustic measurements aided by the flow visualization bring out the nature of influence of the LP clearly. The noise levels on the launch vehicle are minimally affected by the presence of LP unless the jets from the nozzles grow enough to spill over the cutouts and flow along the launch platform. The nozzle standoff distance $L / D_{e}$ and size of the cutouts on the LP are the deciding factors that dictate the influence of the LP because they together account for the jet growth and the subsequent spillovercausing wall jets. This effect is more pronounced at higher $L / D_{e}$ than 

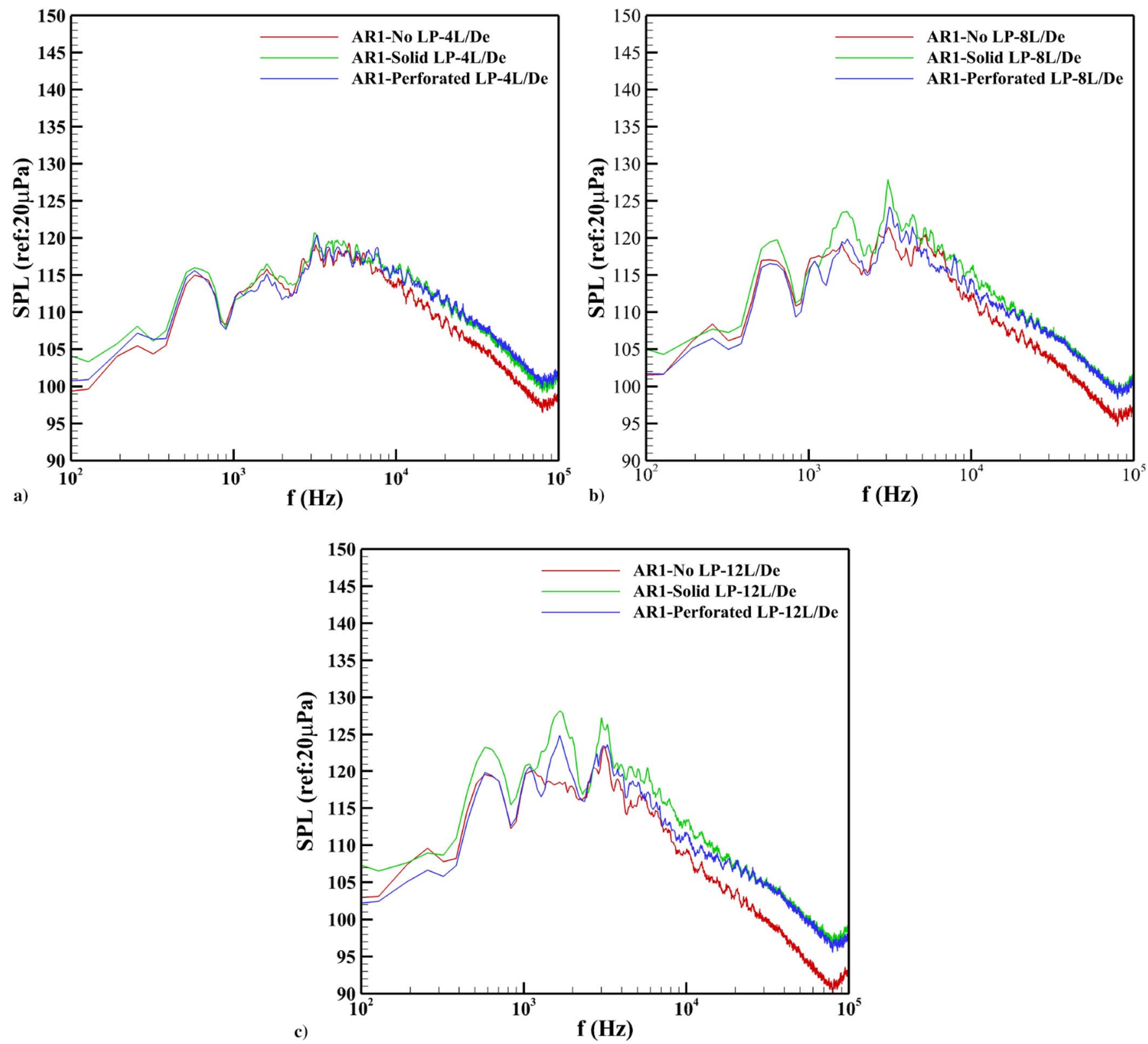

Fig. 13 Comparison of sound pressure levels at AR1 for a) $L / D_{e}=4$, b) $L / D_{e}=8$, and c) $L / D_{e}=12$.

the lower ones. The wall jet created due to the presence of the launch platform, either solid or perforated, results in additional noise sources that effectively increase the noise levels on the launch vehicle.

An analogy could be drawn between the flow of the wall jet over the PLP and flow over the blunt trailing edge of a flat plate with porous surface. Computational studies by Bae et al. [38] on flow over blunt tailing edges suggest that, compared to a solid trailing-edge surface, a porous surface has reduced pressure fluctuations. This was due to the fact that a pressure release mechanism directly reflects as reduction in the strength of dipole sources at the trailing edges and hence reduces turbulent noise. A similar effect could be a possible reason behind the acoustic effectiveness of PLP observed here. There may also exist an optimal porosity of the PLP at which noise reduction achieved is maximum. However, such a conjecture needs further analysis and investigation.

\section{Conclusions}

Flow and acoustic measurements were conducted on a scaleddown launch vehicle and jet blast deflector model inside an anechoic chamber. Experiments were carried out at different nozzle standoff distances $L / D_{e}$ from the launch pedestal, simulating the liftoff of the launch vehicle. Unlike the earlier studies, the present study involves a more realistic simulation of the actual launch environment, where jets from two nozzles impinge on a launch platform with cutouts and subsequently the flow over the jet blast deflector. The results show that the presence of the launch platform between the jet exit and the jet blast deflector modifies the flowfield considerably, increasing noise levels experienced by the launch vehicle especially at higher $L / D_{e}$ ratios, increasing the noise levels at least by $4 \mathrm{~dB}$ at model scales. The introduction of perforations in the launch platform results in reduced the noise levels when compared to the solid launch pedestal case at all $L / D_{e}$ ratios. However, the overall sound pressure level of a perforated launch platform is still higher than for the case without the launch platform.

The results also indicate that a perforated launch platform carries much promise as a viable solution to alleviate acoustic contributions of the launch platform. The existing launch platforms can also be easily modified to incorporate perforations. To overcome any kind of operational hindrance, launch platforms can be can be designed such that the perforations become effective only a few seconds before launch. Moreover, the present investigation shows that launch structure components other than the jet blast deflector, such as the launch platform, also contribute significantly to the overall liftoff 
acoustic levels and that any efforts to reduce liftoff noise will only be complete by estimating these contributions along with those of the jet blast deflector.

\section{Acknowledgments}

The authors would like to thank S. Sudhakar, Ashwin Kumar, and the staff of the Jet Aeroacoustics Research facility for their assistance in carrying out the experiments.

\section{References}

[1] Eldred, K., "Acoustic Loads Generated by the Propulsion System," NASA SP-8072, 1971.

[2] Potter, R. C., and Crocker, M. J., "Acoustic Prediction Methods for Rocket Engines, Including the Effects of Clustered Engines and Deflected Exhaust Flow," NASA CR-566, 1966.

[3] Plotkin, K. J., Sutherland, L. C., and Vu, B. T., "Lift-Off Acoustics Predictions for the Ares I Launch Pad," 15th AIAA/CEAS Aeroacoustics Conference, AIAA Paper 2009-3163, May 2009.

[4] Haynes, J., and Kenny, R. J., "Modifications to the NASA SP-8072 Distributed Source Method II for Ares I Lift-Off Environment Predictions," 15th AIAA/CEAS Aeroacoustics Conference, AIAA Paper 2009-3160, May 2009.

[5] Kudryavtsev, V., and Safronov, A., "Acoustic Environment Resulting in Interaction of Launch Vehicle Main Engines Jets with a Launch Pad Having Closed Long Ducts Like a Tunnel," Progress in Flight Physics, Vol. 3, Jan. 2012, pp. 405-420. doi:10.1051/eucass/201203405

[6] Koudriavtsev, V., "Acoustic Environment at Jet Interaction with a Plate," Proceedings of the 29th Congress (International and Exhibition on Noise Control Engineering (INTERNOISE 2000), Societe Francaise d'acoustique, Nice, France, 2000.

[7] Koudriavtsev, V., and Safronov, A., "Noise Generation at Supersonic Jet Interaction with Inclined Deflector," Proceedings of the INTER-NOISE and NOISE-CON Congress and Conference, Inst. of Noise Control Engineering, 2001, pp. 708-711.

[8] Krothapalli, A., Rajkuperan, E., Alvi, F., and Lourenco, L., "Flow Field and Noise Characteristics of a Supersonic Impinging Jet," Journal of Fluid Mechanics, Vol. 392, Aug. 1999, pp. 155-181. doi:10.1017/S0022112099005406

[9] Elavarasan, R., Venkatakrishnan, L., Krothapalli, A., and Lourenco, L., "A PIV Study of a Supersonic Impinging Jet," Journal of Visualization, Vol. 2, Nos. 3-4, 2000, pp. 213-221. doi:10.1007/BF03181438

[10] Elavarasan, R., Krothapalli, A., Venkatakrishnan, L., and Lourenco, L., "Suppression of Self-Sustained Oscillations in a Supersonic Impinging Jet," AIAA Journal, Vol. 39, No. 12, 2001, pp. 2366-2373. doi: $10.2514 / 2.1243$

[11] Alvi, F., Ladd, J., and Bower, W., "Experimental and Computational Investigation of Supersonic Impinging Jets," AIAA Journal, Vol. 40, No. 4, 2002, pp. 599-609. doi: $10.2514 / 2.1709$

[12] Henderson, B., "The Connection Between Sound Production and Jet Structure of the Supersonic Impinging Jet," Journal of the Acoustical Society of America, Vol. 111, No. 2, 2002, pp. 735-747. doi:10.1121/1.1436069

[13] Nonomura, T., and Fujii, K., "Computational Study of Effects of NearWall Turbulent Structure on Aeroacoustic Waves from a Supersonic Jet Impinging on an Inclined Plate," 17th AIAA/CEAS Aeroacoustics Conference, AIAA Paper 2011-2917, June 2011.

[14] Tsutsumi, S., Fukuda, K., Takaki, R., Shima, E., Fujii, K., and Ui, K., "Numerical Study on Acoustic Radiation for Designing Launch-Pad of Advanced Solid Rocket," 44th AIAA/ASME/SAE/ASEE Joint Propulsion Conference \& Exhibit, AIAA Paper 2008-5148, July 2008.

[15] Tsutsumi, S., Kato, S., Fukuda, K., Takaki, R., and Ui, K., "Effect of Deflector Shape on Acoustic Field of Launch Vehicle at Lift-Off," 47th AIAA Aerospace Sciences Meeting Including the New Horizons Forum and Aerospace Exposition, AIAA Paper 2009-0328, Jan. 2009.

[16] Kandula, M., "An Experimental and Numerical Study of Sound Propagation from a Supersonic Jet Passing Through a Rigid-Walled Duct with a J-Deflector," International Journal of the Acoustics and Vibration, Vol. 11, No. 3, 2006, pp. 125-131.

[17] Nakai, Y., Fujimatsu, N., and Fujii, K., "Experimental Study of Underexpanded Supersonic Jet Impingement on an Inclined Flat Plate," AIAA Journal, Vol. 44, No. 11, 2006, pp. 2691-2699. doi:10.2514/1.17514
[18] Kandula, M., and Vu, B., "Scale Model Experiments on Sound Propagation from a Mach 2.5 Cold Nitrogen Jet Flowing Through a RigidWalled Duct with a J-Deflector," NASA TM-2003-211186, April 2003.

[19] Kandula, M., "Sound Radiation from a Supersonic Jet Passing Through a Partially Open Exhaust Duct," Journal of Vibration and Acoustics, Vol. 133, No. 6, 2011, Paper 064503. doi:10.1115/1.4004671

[20] Worden, T., Gustavsson, J., Shih, C., and Alvi, F. S., "Acoustic Measurements of High-Temperature Supersonic Impinging Jets in Multiple Configurations," 19th AIAA/CEAS Aeroacoustics Conference, AIAA Paper 2013-2187, 2013.

[21] Dougherty, N. S., and Guest, S. H., "A Correlation of Scale Model and Flight Aeroacoustic Data for the Space Shuttle Program," 9th AIAA Aeroacoustics Conference, AIAA Paper 1984-2351, 1984.

[22] Gély, D., Elias, G., Bresson, C., Foulon, H., and Radulovic, S., "Reduction of Supersonic Jet Noise. Application to the Ariane 5 Launch Vehicle," 6th AIAA/CEAS Aeroacoustics Conference, AIAA Paper 2000-2026, June 2000.

[23] Ignatius, J. K., Sathiyavageeswaran, S., and Chakravarthy, S. R., "HotFlow Simulation of Aeroacoustics and Suppression by Water Injection During Rocket Liftoff," AIAA Journal, Vol. 53, No. 1, 2015, pp. 235-245. doi:10.2514/1.J053078

[24] Panda, J., "An Experimental Investigation of Screech Noise Generation," Journal of Fluid Mechanics, Vol. 378, Jan. 1999, pp. 71-96. doi:10.1017/S0022112098003383

[25] Panda, J., and Mosher, R., "Identification of Noise Sources in a Model Scale Lift-Off Test Using a Microphone Phased Array," 50th AIAA Aerospace Sciences Meeting, AIAA Paper 2012-1171, Jan. 2012.

[26] Panda, J., and Mosher, R., "Use of a Microphone Phased Array to Determine Noise Sources in a Rocket Plume," 49th Aerospace Sciences Meeting, AIAA Paper 2011-974, 2011.

[27] Ishii, T., Tsutsumi, S., Ui, K., Tokudome, S., Ishii, Y., Wada, K., and Nakamura, S., "Acoustic Measurement of 1:42 Scale Booster and Launch Pad," Proceedings of Meetings on Acoustics, Vol. 18, No. 1, Acoustical Soc. of America, 2014, Paper 040009. doi: $10.1121 / 1.4879265$

[28] Panda, J., Mosher, R. N., and Porter, B. J., "Noise Source Identification During Rocket Engine Test Firings and a Rocket Launch," Journal of Spacecraft and Rockets, Vol. 51, No. 6, 2014, pp. 1761-1772. doi:10.2514/1.A32863

[29] Kawai, S., Tsutsumi, S., Takaki, R., and Fujii, K., "Computational Aeroacoustic Analysis of Overexpanded Supersonic Jet Impingement on a Flat Plate With/Without Hole," Proceedings of the ASME/JSME 2007 5th Joint Fluids Engineering Conference, American Soc. of Mechanical Engineers Paper FEDSM2007-37563, 2007, pp. 1163-1167.

[30] Wiley, A., Choutapalli, I., Kumar, R., and Alvi, F., "Noise and Flowfield Characteristics of a Supersonic Jet Impinging on a Porous Surface," 48 th AIAA Aerospace Sciences Meeting, AIAA Paper 2010-0273, Jan. 2010.

[31] Kinzie, K., Schein, D., and Solomon, W., "Experiments and Analyses of Distributed Exhaust Nozzles," 8th AIAA/CEAS Aeroacoustics Conference \& Exhibit, AIAA Paper 2002-2555, June 2002.

[32] Ahuja, K. K., Alvord, D. A., Mattingly, J., Mittelman, J., Dickey, D., and Alvord, D. A., "Thoughts on Use of University-Scale Rocket Models to Study Launch Acoustics," 20th AIAA/CEAS Aeroacoustics Conference, AIAA Paper 2014-3056, 2014.

[33] Karthikeyan, N., Verma, S. B., and Venkatakrishnan, L., "Development Installation and Calibration of Jet Aeroacoustics Research Facility," CSIR-NAL Rept. E-0-219, Bangalore, India, 2010.

[34] Himelblau, H., Kern, D. L., Manning, J., Piersol, A., and Rubin, S., "Dynamic Environmental Criteria," NASA Technical Handbook 7005,2001

[35] Viswanathan, K., "Aeroacoustics of Hot Jets," Journal of Fluid Mechanics, Vol. 516, Oct. 2004, pp. 39-82. doi:10.1017/S0022112004000151

[36] Hargather, M. J., and Settles, G. S., "Retroreflective Shadowgraph Technique for Large-Scale Flow Visualization," Applied Optics, Vol. 48, No. 22, 2009, pp. 4449-4457. doi:10.1364/AO.48.004449

[37] Munday, D., Gutmark, E., Liu, J., and Kailasanath, K., "Flow Structure and Acoustics of Supersonic Jets from Conical Convergent-Divergent Nozzles," Physics of Fluids, Vol. 23, No. 11, 2011, Paper 116102. doi:10.1063/1.3657824

[38] Bae, Y., Jeong, Y., and Moon, Y., "Effect of Porous Surface on the Flat Plate Self-Noise," 15th AIAA/CEAS Aeroacoustics Conference, AIAA Paper 2009-3311, May 2009. 